\title{
Transcendental Philosophy, The History of Psychology Kant and Freud.
}

\author{
Dr. Michael R.D. James,
} PhD Uppsala University, Sweden

Former Representative of Sweden at the World Schools Debating Council

\section{Abstract}

Kant is not generally recognised to be an Aristotelian hylomorphic Philosopher because of his extension of logic into Philosophical Psychology in the form of Transcendental Logic. This extension is a natural articulation of hylomorphic metaphysics. Aristotle's 4 kinds of change, 3 principles, and 4 "causes" are all transformed into the Kantian system of categories of judgement and also transposed into the faculties of sensibility, understanding, and reason. The principles of noncontradiction and sufficient reason obviously have origins in Aristotelian logic and Metaphysics. Freud claims that he is writing the Psychology that Kant would have written had he written subsequent to the "divorce" between Philosophy and Psychology in 1870 but it is clear that Freud too must be considered a hylomorphic Psychologist. This latter claim must be true if it is the case that Kant can be regarded, a hylomorphic Philosopher. Freud regards Consciousness and psychological residues (rituals) that we find in institutions as vicissitudes of Instinct. Instinct is here of course a philosophical concept possessing an aim, an object, a bodily source and a demand for motor activity. Early vicissitudes of instincts are narcissistically based and give rise the genesis of a strong ego under favourable circumstances. Freudian theory correctly interpreted ought to give rise to ethical theory of the type we find in Kant. This is a requirement for theories that we find in the arena of transcendental psychology.

Keywords: philosophy; education; psychology; human science; Kant; Freud.

\section{Introduction $^{1}$}

The Golden Age of Ancient Greece, the Renaissance, and the Enlightenment are three historical ages with significant underlying Philosophical and Educational intent. The image of Ariadne's thread in the labyrinth where the Leviathan-like Minotaur dwells is used to illustrate the hidden cultural phenomenon of continuity of ideas that sustain our cultural journey throughout ages.

The ideas of Aristotle and Kant are key arenas of achievement in our cultural History. Aristotle's influence waned in the journey of ideas up to and including the Philosophy of Rousseau. His ideas waxed in the Philosophy of Kant and the subsequent

${ }^{1}$ Copyright of the Author. Revised version by the book "A Philosophical History of Psychology, Cognition, Emotion, Consciousness and Action", Michael R. D. James. 
waning of Kantian Philosophy at the hands of "modern thinkers" influenced by Hegel, Science, and Economics. The "modern age" is in our eyes a misnomer because the next candidate for the title "Age" must contain events of greater significance than landing on the moon and the creation of atomic bombs. The next age will be the age of Philosophical Cosmopolitanism brought about by the manifold of globalisation forces we are experiencing today

Kant begins his work "Anthropology from a Pragmatic point of view" with a discussion of consciousness of one's self:

"The fact that the human being can have the " $I$ " in his representations raises him infinitely above all other living beings on earth. Because of this, he is a person and by virtue of the unity of consciousness through all changes that happen to him, one and the same person--i.e. through rank and dignity an entirely different being from things, such as irrational animals, with which one can do as one likes. This holds even when he cannot yet say "I" because he still has it in thoughts, even if they do not have a special word to express this concept of "l". For this faculty (namely to think) is understanding. But it is noteworthy that the child who can already speak fairly fluently nevertheless first begins to talk by means of "I" fairly late (perhaps a year later) in the meantime speaking of himself in the third person(Karl wants to walk, to eat etc.). When he starts to speak by means of the "I" a light seems to dawn on him, as it were, and from that day on he never again returns to his former way of speaking. Before he merely felt himself now he thinks himself. The explanation of this phenomenon might be rather difficult for an anthropologist." (Anthropology P. 15).

Indeed it might be more or less difficult for the anthropologist to talk about thinking at all but especially difficult if his methodology of detection/description/explanation of the phenomenon he is observing is confined to third-person language which as Hume suggested finds it impossible to "find" the self that needs description or explanation. As we know Hume's work awoke Kant from his dogmatic slumbers where his theorizing was orbiting in a universe that included the sun of reason and the moon of sensibility. The faculty of the understanding in the university of the mind which embraces the self and causality was clearly missing in Kant's universe as it was in Hume's account which also claimed that we not only cannot observe a self, we cannot observe and describe "causality" because all we "see" are two independent events juxtaposed in time. Hume was, of course merely the medium for the transmission of an empirical philosophy that could not see the Cartesian rational wood for the trees. Empiricists could not see that there was a form of "logic" concerned with universality and necessity, a form that required categories of judgment if this transcendental logic was to reach into the world we sensibly experience. This "logic" also required, as Kant pointed out in his First Critique, that the "I think" must accompany all our representations, and this includes representations of the sensory world in terms of the categories of judgments. Kant then found the initial division of the university of 
the mind into the faculties of sensibility, imagination, and reason to be inadequate to resolve the philosophical disputes of his time, especially those between the empiricists and the rationalists: thus his introduction of the understanding with its categories of judgments. Rationalists like Descartes, who tried to account for all mental activity firstly in terms of the imagination (he tried to imagine away his body!) and secondly a form of logic(mathematical?) was also a target for Kant's Critical Philosophy. The Empiricist response to Descartes was well characterised by the Analytical Philosopher R. S. Peters in his essay "Observationalism in Psychology":

"They put a salutory stress on observation as opposed to a deduction from axioms and substituted for Descartes simple natures, sensory atoms collected by simply looking at Nature. They maintained not only that scientific laws were descriptions of invariable sequences of these sensory atoms but that things also, including ourselves and others, were clusters of such sense-data built up as a matter of psychological fact, by correlating such atomic sense data. Hume's isolated and incorrigible impressions served a singular epistemological function. Locke and Hume established a tradition both of psychology and philosophy and the psychological tradition was strongly influenced by their philosophical views about the correct way of obtaining knowledge." (Psychology and Ethical Development R S Peters P.28).

Ideally one might have hoped that Kant's Critical Philosophy would have put both Philosophy and Psychology on the track already beaten out by Aristotle's hylomorphic theory. This did not happen. Instead, a Heraclitean/Hegelian dialectic was used to beat out a new path that would form our modern world into a flux of materialistic and dualistic phenomena. On this path, there is located the event of Psychology breaking its philosophical moorings, in order to reconcile the scientific method with the so-called "subject-matter" of consciousness. In the opening quote from Kant and in the following passages of his Anthropology, we find Kant speaking of consciousness hylomorphically as a form of mental activity. When it, was discovered by the early Psychologists in the late nineteenth century that the experimental method could not say anything meaningful about the concept of consciousness, in spite of the definition of Psychology as the science of consciousness, there was an opportunity to return to the Kantian idea of consciousness being a "form" or a principle of mental activity. Instead what happened was an alliance of a methodological obsession with the scientific materialists and a new subject matter was sought for and found, namely behaviour. Behaviour, it was argued, could be observed and described/explained from a thirdperson point of view and for a second time in philosophical history(Hume's failure to "observe" the self, being the first) the self was analytically removed from Philosophy and Philosophical Psychology. Support for this removal came from a scientific method that had developed since the time of Francis Bacon, characterised thus by R S Peters:

"The inductive account of scientific method which is an alternative way of stating observationalism, postulated the careful and meticulous collection of data by "pupils 
of Nature", the cautious generalisation which must not go beyond the data, and the "interpretation" which emerged when a judicious man like Francis Bacon surveyed the tables of classified data. This picture of the scientists in action combined with the Kantian aphorism that a discipline is as scientific as it contains mathematics led to the tacit acceptance of the view that the scientist proceeds by observing events in Nature, measuring them, noticing correlations or laws between sets of measurements, and finally relating laws under theories." (P. 28)

So here we have three leading navigational stars guiding scientific activity, observation, subject matter, and measurement. Kant would not have objected to these guidelines per se if they were accompanied by an appropriate attitude that was not that of a student of nature obsessing over a method and measurements that are being made. These guidelines, he might have argued, could occur in another context of a determined judge armed with his a priori concepts and principles, putting his questions to Nature and demanding answers that were informative, before making a final judgment. It is interesting to note, is it not, that behind this putatively "objective" characterisation of the scientist as a student of Nature there is a psychological profile that may be prejudicial to the outcome of the investigative process. Putting this investigative process into the context of a legal tribunal and the law widens the scope of how investigations proceed. The judge in the tribunal is waiting to be presented with evidence of the breach of the law. He is not a student waiting for the evidence to inform him what the law is. The law is the apriori principle in this process. He puts questions to the witnesses and to legal counsel when the law requires more information. This is Kant's context: a context of discovery (questio factii) guided by a context of justification (questio Juris). In the Empirical idea of the appropriate context, we see that the context of discovery is primary and the context of explanation/justification virtually non-existent, hence the priority of sense and imagination over understanding and reason. The difference between these two types of context and types of theory could not be greater and resembles the difference between categorical and hypothetical forms of judgment. One might also add in parenthesis here that the type of Science proposed by Bacon's inductive method is more suitable for the kind of Science Bell, the physicist, conducted in relation to his theory of gases than it was for the type of science we find in Newton's Principia. The very title of Newton's work, "Principles" is itself suggestive of its philosophical priorities (he called his investigations "Natural Philosophy"). Newton's law of the conservation of matter and energy are not a result of the observation of matter and energy in reality but possessed a transcendental apriori character. Kant continues his characterization of the "I" in the "Anthropology" in an Aristotelian hylomorphic spirit by referring to its occurrence in child development. He points to the fact that when the child begins to think from the first-person point of view there is a risk of egoism which must be transcended by what he calls pluralism if the child is to proceed with his life in a spirit of understanding and reason, insofar as his fellow humans are concerned: 
"The opposite of egoism can only be pluralism, that is the way of thinking that is not concerned with oneself as the whole world, but rather regards and conducts oneself as a mere citizen of the world. This much belongs to anthropology." (A P. 18).

Here, two important points emerge. Firstly Kant immediately locates theory in an ethical context of justification. Secondly, he is suggesting that the source of objectivity, universality, and necessity resides in this "I" that appears to be both a theoretical and a practical entity. This flies in the face of both empiricism and rationalism and the tendency of both positions to see in the difference between the theoretical and practical, a fundamentally divided mind: a knowing mind and a desiring mind. The above quote also, in referring to oneself as a citizen of the world, is clearly suggesting that practical reasoning and understanding are going to be important components in both ethics and political philosophy. Kant then continues his reflections, by characterising the theoretical aspect of the "I think" that accompanies all our representations. He invokes the role of voluntary consciousness and characterises this power or capacity in two ways. Firstly, I can pay attention to my representations in order to allow the imagination, or what he calls the act of apperception, to connect the representation we are focusing upon with other representations. Secondly, I also possess the power to abstract in relation to the representation I am paying attention to, and thereby prevent connection with certain other representations. It is this latter power that is responsible for the universality of a concept insofar as Aristotle is concerned: in this theory, the concept abstracts from the differences between objects and events in the world that fall under the concept's extension. It does this in accordance with the knowledge that an organiser of representations has of the form or principle of the object or event designated by the concept. The concept is thus acquired through the discriminatory power of perception in conjunction with the comparative and selective power of the memory of a number of associated representations that have in turn been connected perhaps by the role of imagination in the multi-layered sequence of cognitive activities leading up to the act of apperception in which the "I" thinks about the manifold conceptually. Kant illustrates this process in his First Critique by referring to the concept of body:

"The concept of body, for instance as the unity of the manifold which is thought through it, serves as a rule in our knowledge of outer appearances. But it can be a rule for intuitions only insofar as it represents in any given appearance the necessary reproduction of their manifold, and thereby signifies unity in our consciousness of them. The concept of body, in the perception of something outside us, necessitates the representation of extension, and thereby with Representation of impenetrability, shape, etc." (Critique of Pure Reason A106)

Here we are taken on an excursion into the theoretical hinterland of transcendental Philosophy and by implication transcendental psychology for which there are two different deductions, one objective and one subjective. In the subjective deduction 
from the first edition of the work, the powers of the subject are characterised in terms of three syntheses: a synthesis of apprehension, a synthesis of reproduction attributed to the imagination, and a synthesis of recognition in a concept attributed to the understanding. The transcendental act of apperception of the "I think" is not a part of the subjective deduction but it is clearly a part of the process of understanding that arrives at a conceptualisation of the object. The objective deduction concentrates upon the transcendental conditions of experience, in particular on the notions of an objective necessary unity of the "I think" or self-consciousness, that is related to the logical or categorical forms of judgment that aim at knowledge or justified true belief. This reference to the categories of judgment ensures that our concepts truly conceptualise something, namely an external object or event in the external world. The subjective deduction, it has to be said, sometimes reminds one of what philosophers today call the context of discovery, namely a bottom-up approach toward knowledge in which an account of the process by which we acquire knowledge is of course important. The objective deduction, on the other hand, reminds us of the context of explanation/justification in which the attitude of a sober determined judge of nature replaces that of a curious hypothetically minded student of nature that cites the workings of an actualisation process in which powers build upon powers. The effect of the two deductions on the reader is prodigious and contributes to a context of justification in which we are made aware of the fact that the conceptual form of self-consciousness is related universally and necessarily to the conviction that we are dealing with an objective world where objects and events really exist in the form in which we are experiencing them (they are empirically real). Reality, of course, is also noumenal and thereby uncharacterisable or transcendentally ideal, as Kant puts it, but he adds that we can only think such a reality, not know that it exists: there is, in other words, no proof or possible demonstration of noumenal reality. The opening reference to consciousness in the Anthropology is undoubtedly a part of the subjective deduction of the categories of judgment, but it is important nevertheless to note that there is, firstly, an imaginative component that connects representations which resemble each other in some respect, as well as secondly, an understanding component which can and does abstain from this connection in terms of resemblance in favour of a rule of a concept that abstracts from the differences between objects and events and the representations of them we experience in space and time. The rule of the concept, then, represents what these objects and events have in common, i.e. resemblance supervenes after the work and not before, as Hume claimed in his theory of the association of impressions. It is important to note that the rule is like a principle or a law in that it assists in the process of picking out objects or events that can then be subsumed under the law or principle: the concept behaves judiciously and not hypothetically because the process simultaneously justifies or explains the process of subsumption. In the objective deduction, Kant speaks of the figurative synthesis of the imagination and an intellectual synthesis of the understanding. We discussed in the 
previous essay, the aesthetic judgment in which judgments of free beauty are made at a pre-conceptual stage. The final explanation or justification of such judgments is, as we noted, subjective, based on a feeling of the harmony of the free play of the faculties of the imagination and the understanding. This judgment expresses what one feels rather than what one thinks in the context of explanation/justification. This is why we are disinterested, not interested in the existence of the object: intellectual interest is always in the context of the truth that is necessarily related to the existence of objects and events. When in the case of an aesthetic judgment we speak with a universal voice about our feeling, we are not claiming to share knowledge of a truth but rather hoping that all subjects use their common sense or an imaginative power we all hold in common. The shift from deliberating about the "I" as a theoretical entity to deliberation about it as a practical entity occurs almost seamlessly in the Anthropology when Kant states the following:

"To be able to abstract from a representation, even when the senses force it on a person, is a far greater faculty than that of paying attention to a representation, because it demonstrates a freedom of the faculty of thought and the authority of the mind in having the object of ones representations under ones control.... In this respect, the faculty of abstraction is much more difficult than that of attention, but also more important when it concerns sense representations." (Anthropology P. 20)

This is an excellent transition into practical transcendental psychology and there are in this discussion clear connections to our earlier discussions on observation, when Kant discusses the mental condition of melancholia that he connects with the obsessional concern of observing oneself. Sufferers from melancholia, Kant argues, speak as if they are listening to themselves and seem to want to present outwardly an illusion of their personality. Naturally, the representations of such mentally unstable people arouse the suspicions of those around them who come to believe that they are witnessing an intention to deceive. Kant comments further:

"This eavesdropping on oneself is either already a disease of the mind (melancholy) or leads to one and to the madhouse." (A P.22)

Kant also explains why this obsession is unhealthy. There is not a stable "something" to think about--representations come and go in Heraclitean fashion, and the river of our representations runs on and on without any organising activity of an "I think". The "I think" not only fixes attention on a particular representation(thinks something) but proceeds further in accordance with the category of judgments to seek the truth by thinking something about something, in what Heidegger called a veritative synthesis. It appears from this that Kant was well ahead of his time in suggesting that serious mental disease(psychosis) is to be philosophically characterised in terms of deficiency of the conceptual power of the understanding. Freud claimed that his Psychoanalytical theory was Kantian and it might have been partly this ontological 
characterization of mental disease that he was thinking about when he proclaimed an alliance with Kant. Certainly the Freudian triumvirate of principles: the energy regulation principle(regulating the energy levels of neuronal and organic systems), the pleasure-pain principle(regulating desires) and the reality principle(regulating our relation to the external physical world and society) is an echo of Aristotelian hylomorphic thought, but it also contains substantial elements of Kantian thinking. Kant, for example, speaks about "obscure" representations that are not conscious and this clearly anticipates the Freudian ideas of the preconscious and unconscious mind. Kant, however, believes that the study of such representations do not belong to the study of what he calls, "pragmatic anthropology" which is defined in terms of the investigation of what man as a free-acting being makes of himself(or should make of himself). Obscure representations fall, rather into the domain of physiological anthropology that is defined in scientific terms of what nature makes of man. Such scientific investigations can be observation-based or purely speculative. Kant points out that observations are limited because the observer must know how to let nature run its course before making any judgment. Speculative physiological anthropology is, according to Kant merely a waste of time. Freud's "Project for a Scientific Psychology", which Freud himself burned, probably falls in the categories of both observationbased and speculative Psychology. In his more mature reflections, however, Freud taught us about the death instinct and how man fashions the weapons of his own destruction in his own mind by failing to conceptualize his world adequately. There is a reliance instead on a form of imagining that connected representations in terms of what he called the principle of the primary process. Imagining is, of course, "thinking" in the popular sense of the term, especially when it is in immediate proximity to the operation of a will that, for example, is intent on killing itself, but it is not so for Kant, who would probably classify this form of pathological activity of the imagination as an obscure form of representation. (The law, as we know, used to classify the death of those who commit suicide in terms of the description "whilst the balance of the mind was disturbed"). Clear and distinct representation is what brings order into a disordered world, viewed from the perspective of the categories and concepts of the understanding. There are of course levels of understanding ranging from the judgments of common sense, where rules are applied judiciously to cases, to the judgments of the man of science, like Freud, who understands the nature and origins of the rules (their universality and necessity) and their a priori nature. "Primary process "thinking"', in Kant's ontological scheme would fall into the class of things and events that happen to man, and this is the reason why "thinking" is placed in quotation marks. This form of activity belongs more to the faculty of sensibility when it is following the pleasure-pain principle than to the faculties of understanding and reason that follow what Freud calls the "Reality Principle". Freud's characterisation of the death instinct operating in melancholia, a condition he found so difficult to treat because patients suffering from this malady were so intent upon self-destruction, refers to instinctive primary process 
mental activity which is the psychical representation of an endosomatic continuously flowing source of stimulation that can be analysed into:

1. an impetus (a relation to energy regulation).

2. an aim (to abolish the source of the stimulus that is disturbing the equilibrium of the organism)

3. an object (that through which the aim is actually achieved)

4. a source (the somatic activity responsible for the stimulation)

If we are dealing with a balanced mind, instinct may be modified by the perception of the environment, the development of speech (e.g. the acquisition and use of the "I") and learning processes that teach the agent to postpone the motor discharge of the stimulation, thus exchanging a certain ambiguous pleasure of the moment for a more lasting long term pleasure in the future. What we witness in such a process is the installation in the mind of the Reality Principle (Freud's term) that for Kant would be the accompanying of all representations by the "I think". This mental activity for Freud would be involved in the formation of the mental agency he refers to as the "ego", whose first task and priority is to protect the body from harm. It is this agency of the mind that is lacking in the melancholic when his seemingly bottomless unhappiness causes him to want to end his life, in what Kant would regard as an unethical act(on the grounds that it is a practical contradiction to use one's life to end one's life). We can see in the above characterisation of the formation of the ego, the role of mourning which will always be involved when we are dealing with the loss of an object of our desires. The giving up of the uncertain ambiguous pleasure of the moment is not just a momentary mechanical automatic switch from one mode of operation to another but rather a long drawn out work of de-cathecting one type of object and cathecting or investing energy in another type of object. It is this type of mental work that it is so difficult to persuade the melancholic to engage in, because there is in Kantian language no "I" or "ego" to do the work concerned. We should recall in the context of this discussion that melancholia (depression) is a serious mental disorder characterised by psychiatry as a psychosis. Other forms of mental illness where there is an "I" but it is not fully formed are easier to treat and are called neuroses by psychiatrists. Here, rather, the ego is supposed enslaved by the imagination and its pleasures and pains. The pleasures and pains of a developed ego are organised in accordance with time conditions where memories of traumatic events will fade naturally with the passing of time: such fading memories will not flood consciousness every time they are remembered. Kant did not dive into the depths of the logic of the emotions and attempt to identify regions of the mind such as the unconscious, as Freud did, but it should also be remembered that Freud's work in this area was a response to the needs of his mentally ill patients. Avoidance of anxiety for Freud was also the mark of certain representations that had difficulty in emerging into the system of consciousness. 
Much of Freud's later work was devoted to mapping the so-called "defence mechanisms" of the mind that continue to prevent emotionally charged representations from "surfacing" in consciousness. This was in itself an important discovery because a major condition of learning is that when one is learning, what one is learning about must in some sense be present to consciousness. Instincts, for Freud, express the body to the mind, and sexuality is obviously an important activity of the body, considering its special relation to both reproduction and the biological/ psychological pleasure associated with it. Sexuality and imagination are also intimately related, and in Freud's theory are associated with the primary process (of imaging). The "agent" of this process is probably not correctly termed an "I" or a self, but is perhaps better characterised as a narcissistic centre of mental activity in which distinctions between subject and object are characteristically blurred. Here, the centre of activity is the sole source of pleasure which if denied can result in the centre treating itself as an object and even destroying itself in an ultimate act of hatred. There are also obvious connections between narcissism and sexuality, but a full explanation of this relationship requires a hylomorphic approach to the development of sexuality, the ego, and its precipitate, the superego. In the process of this development the libido--"that force by which the sexual instinct is represented in the mind" must be part of a larger life-force which will assist in transforming libido, from an auto-erotic force connected to an organ of pleasure, into a love for objects devoid of the hate and aggression typical of those suffering from narcissistic personality disorders. In Freud's theories, the libido can be "sublimated" during phases or stages where pleasure locations shift from different regions of the body to the mind as a whole that Freud prefers to characterise in terms of his "agencies", the ego and the superego. We mentioned that the first task of the ego was to protect the body, but it's higher more conscious functions(requiring learning and knowledge) are to love and to work in ways which are "pluralistic", to use Kant's expression from the Anthropology, or "anaclitic" to use Freud's term. This process of moving from organ pleasure to object choice purged of all narcissistic influence is hylomorphic. The moving of pleasure from region to region of the body and finally into the mind of the subject is guided by the pleasurepain principle or what Aristotle would call a "form". The preparedness to give up this "form" of organising pleasure indicates that this "form" of the pleasure-pain principle becomes "Matter" which is in its turn "formed" by a new principle, the Reality Principle that is important for the activities of loving and working and which is prepared to postpone pleasure perhaps for an indefinite period of time. Obviously, in characterising this actualisation process, the explanations we use to explain the operation of these principles must be complex and hylomorphic, i.e ultimately a complete explanation of the process will require the 4 different kinds of explanation Aristotle referred to in his theory of change. These explanations will include a reference to a teleological form of explanation that refers to an idealistic end to this process of development. It is, however, fascinating to note that the idealistic teleological terminus point for the 
powers of the mind, are for both Kant and Freud, moral or ethical. Kant's Anthropological reflections are clearly aimed not at a modern lonely solipsistic individual loving and working for his own selfish ends but rather at what Kant recognises to be a cosmopolitan citizen of the world. It is not certain that Freud would have shared this very politically oriented vision but he definitely agrees with Kant over the vision of man dutifully loving and working in a form of civilisation he may well be discontented with(because it is not cosmopolitan?) The Freudian superego is Kantian to its core and shares also a commitment to hylomorphism that is apparent in the actualising process of the formation of the superego in accordance with a reality principle committed not just to the truth but also to "The Good", an ancient Platonic theme. That the superego should emerge from "sexuality" broadly defined is also a Platonic theme and conjures up a picture of a barefooted Eros padding about the streets of Athens searching for appropriate forms of knowledge to improve his life. Eros is dogged by Thanatos and also must submit to the demands of Ananke, and this Platonic allegory is a part of Freud's more mythological characterisation of a theory otherwise composed of extremely technical language. Kant's commitment to what causes awe and admiration in himself is inscribed upon his gravestone in Königsberg: "the starry heavens above and the moral law within". These are more Aristotelian than Platonic, more sublime than mythological. Morality, for Kant, as it was for Aristotle is not merely a matter of arriving at a life-goal but also included the way in which one journeyed toward that goal in one's life. The Greek term Areté that means both virtue and excellence denotes doing the right thing at the right time in the right way. This is a critical test of "Good" character and will result in a state of Eudaimonia which is also one of those interesting words that both characterises the way in which one does something (good spirited) but also the telos of such activity(the flourishing life). Kant and Aristotle would have both agreed upon the fact that we choose the way we lead our lives and to the extent that the end result lies in our power, the end result as well. Both would have also agreed that human finitude is such that whether or not one would achieve the end result (a flourishing life) may depend upon whether we are in fact rewarded for the efforts we make. This latter is, for both Philosophers, up to the divine forces or principles governing the universe, divine forces which we hope will provide us with a flourishing life (if we are worthy of one). Freud shows no obvious signs of agreeing with either Kant or Aristotle on this issue and appears to rest his case with the more myth-influenced Plato. We, like Eros, can live, love and work with every fibre of our being to create our civilisation but, for Freud, at the end of this process we might have to live with the thought that all our efforts were not worth the result (reminding us of the ancient prophecy quoted in the Republic that everything created by man is doomed to destruction). We may, that is, have to resign ourselves to our fates (Ananke) and live in a state of discontent. Kant recognises this sentiment when he refers to everyday life as a life of melancholic haphazardness but he transcends this cynical position and offers us some hope on the condition that we are worthy of the life of complete 
happiness. It is certainly the case that much of Freudian theory relating to the instincts falls into the Kantian domain of physiological anthropology because as Kant maintains in his Anthropology:

"in regard to the state of its representations, my mind is either active and exhibits a faculty or it is passive and consists in receptivity. A cognition contains both joined together, and the possibility of having such a cognition bears the name of cognitive faculty--from the most distinguished part of the faculty, namely the activity of the mind in combining or separating representations from one another. Representations in regard to which the mind behaves passively and by means of which the subject is therefore affected (whether it affects itself or is affected by an object) belong to the sensuous faculty. But ideas that comprise a sheer activity(thinking) belong to the intellectual cognitive faculty. The former is called the lower, the latter the higher cognitive faculty. The lower cognitive faculty has the character of passivity of the inner sense of sensations: the higher, of the spontaneity of apperception, that is, of pure consciousness of the activity that constitutes thinking. It belongs to logic(a system of rules of the understanding) as the former belongs to psychology(a sum of all inner perception under laws of nature) and establishes inner experience." (A P.29-30)

The difference here in Freudian terms is perhaps that between the organisation of representations jointly by the energy regulation and pleasure pain principles governing the lower cognitive faculty, an organisation that does not appear to involve higher-level consciousness, and representations organised by the reality principle which governs the active higher cognitive faculty, a faculty that does involve higherlevel consciousness and also actively follows the laws of logic and the rules of the understanding. In Aristotelian terms, the lower sensuous cognitive faculty is the material the mind uses in its representations and which accounts for the passivity of the representation. Kant, in this context, notes the following negative feature:

"Sensibility, on the other hand, is in bad repute. Many evil things are said about it: e.g.

1. that it confuses the power of representation,

2. that it monopolizes the conversation and is like an autocrat when it should be merely the servant of the understanding,

3. that it even deceives us." (A P.34)

Kant then rejects these common criticisms aided perhaps by Platonic ideas. He appeals to Aristotelian hylomorphic theory, claiming that one may grasp a manifold but not yet have ordered it in accordance with the rules of the understanding. The senses, Kant argues, provide an abundance of material that can be combined or separated in various ways in accordance with various principles. Sensibility, Kant argues, cannot be confused or deceived because there is no function of judgment associated with it. Illusion and delusion require a judgment of the understanding to provide a rule with respect to which one is confused or deceived: rules provide a standard of comparison with reality. Kant then goes on to note interestingly that of the 5 senses that constitute 
sensibility, two are pleasure related(smell and taste)and the other three senses appear to have some higher function that relates in some way to reality (providing the material for judgment?). He also notes that we can think of sensibility in terms of the presence of an object (sense perception) but also in terms of the absence of the object (which occurs when we imagine something). Insofar as we are concerned with inner sense we are dealing not with what man makes of himself but rather with what he undergoes when he is affected by the play of his imagination, as the melancholic is when he imagines himself as worthless or the paranoid schizophrenic when he imagines his life is in danger from the FBI. Kant also notes that no organ is associated with inner sense. Kant differentiates in this discussion between what is anthropological and what he regards as merely psychological. The former, as we have pointed out deals with the issues of what man makes of himself in terms of his moral choices that will lead him to become a cosmopolitan citizen of the world, whereas the latter is based on a questionable assumption of a substantial soul that we seemingly (an illusion?) perceive as something within ourselves, something that can reveal itself to some kind of mental investigation or mysterious process of introspection. This search for inner sensations, Kant argues, can only lead to mental instability. This psychological attitude toward the mind could only lead, Kant insists, to retiring into oneself and this state of affairs can only be remedied by a renewed commitment to the external world via the cognitively oriented senses and the application of the laws and rules of the understanding to the material gleaned by these senses--rules and laws that relate both to the external world with its starry heavens and its cities, countries and empires that are such a source of discontentment to their citizens. To lose one's way in such a world is, in Kant's words, to lose ones Tramontano (to lose one's relation to the navigational guide of the North Star). The melancholic has obviously lost his way in the world and is buffeted to death by his own imaginings. In this context, Kant points out that the almost universal fear of death that is natural to all human beings, is a mass illusion, simply because the thought of one's death is impossible, principally because when one is dead one cannot be conscious that one is dead. This is an interesting argument for the necessary connection between thinking and consciousness. Kant discusses dreams in relation to the imagination and sees in dreams the activation of the vital force of life whilst we are sleeping. He points to the lack of continuity between one nights dreams and the next, claiming that this together with the absence of the presence of bodily movements based on choice convinces us that the dream world is not real. Kant claims that the power of imagination is:

"richer and more fruitful in its presentation than sense when a passion appears on the scene the power of imagination is more enlivened through the absence of an object than by its presence." (A P.73)

Memory, Kant claims, is distinguishable from imagination in that it is a reproductive power of the imagination that is able to reproduce its representations voluntarily. 
Memory is necessary for the ordering of experience, Freud notes, and this is actually confirmed by the biological development of the hippocampus: the power of memory is not actualised until around the age that the "I think" is actualised, that is to say around one and a half to three years old. Once the memory is developed, Kant would probably agree that its continuity is essential, along with the continuity of the functioning of the body for the identity of a personal, enduring self that stays the same through a series of experiences. In Freud's theory, certain memories are repressed if sufficient amounts of anxiety become associated with them and/or the ego is not sufficiently developed to bear the anxiety involved. Memory in itself then, is a necessary but not a sufficient condition of the power we possess of anticipating the future, a power necessary for another power, that of practical reasoning:

"Every desire contains a (doubtful or certain) foresight of what is possible through it. Recalling the past(remembering) occurs only with the intention of making foresight of the future possible by means of it; generally speaking, we look about us from the standpoint of the present in order to decide something or to be prepared for something." (A P.79).

There are obvious limits to this form of anticipation when it takes the form of a prophecy of the fate of a person or a people, because obviously, the memory of the prophecy together with a knowledge of the causes operating to bring the fact prophesied about, must be, for Kant, subject to the law of freedom which obviously can alter any prophecy by altering the causes that are bringing certain effects about. For Kant, the higher cognitive faculty is composed of correct understanding (rules), practiced judgment and thorough or complete reasoning(embracing the totality of conditions, i.e. necessary and sufficient conditions). Kant personifies these three cognitive operations in terms of the domestic or civil servant who merely needs to understand his orders in order to obey them, an officer who has to understand more abstractly which principle to apply in particular cases, and the general that needs to make judgments on all possible hypothetical cases and may even have to construct new principles for totally new situations. Kant summarises his position in the following terms:

"Now if understanding is the faculty of rules, and the power of judgment the faculty of discovering the particular insofar as it is an instance of these rules, then reason is the faculty of deriving the particular from the universal, and thus of representing it according to principles, and as necessary... The human being needs reason for every moral (consequently also religious) judgment, and cannot rest on statutes and established customs. Ideas are concepts of reason to which no object given in experience can be adequate. They are neither intuitions (like those of space and time) nor feelings(such as the doctrine of happiness looks for), both of which belong to sensibility. Ideas are, rather, concepts of a perfection that we always approach but never completely attain." (A P.93-4) 
Kant then specifically discusses the weaknesses and illnesses of the soul in relation to its cognitive faculty and fixates upon the psychic conditions of melancholia and what he calls mental derangement. In melancholia: In the case of mental derangement there is:

"an arbitrary course in the patient's thoughts which has its own(subjective) rule but which runs contrary to the (objective) rule that is in agreement with laws of experience." (A P.96)

Kant refers here to "delirious raving" and "delirium". It appears also as if he believes that derangement is a more serious condition than melancholia thus confirming the Aristotelian notion of a continuum of points or stages or phases on a line of development stretching teleologically toward the potential of perfect rationality in accordance with the idea of Reason. In modern psychoanalysis this concept of a continuum correlates with what Melanie Klein would call a difference between the paranoid-schizoid position (derangement) and the depressive position (melancholia). In the former case, the ego and its objects are split in terms of the good and the bad (part-objects) and the latter, where the ego has lost its most valued object and identifies with the loss of that object in terms of its relation to its own life. Underlying the above talk of objects is the operation of the energy regulation principle and the pleasure-pain principles. This operation is in accordance with an account of pleasure and pain that we can in fact find in the Anthropology, in a chapter entitled "On the Feeling of Pleasure and Displeasure". The risks with such a project is that of descending into the depths of describing the material substrate of these operations: a risk Freud took only to abandon and finally appeal to Platonic mythology at the end of 50 years of writing about these principles. Kant's characterisation begins with a classification of pleasures into, firstly, sensuous pleasures and, secondly, intellectual pleasures. These are further divided into two classes: sensuous pleasures are organic (e.g. the enjoyment of good wine) and reflective(aesthetic judgments of taste) and intellectual pleasures are divided into those that are representable by concepts and those that are representable through ideas. The following quote elucidates the feeling of sensuous pleasure and there is a clear reference to energy regulation:

"One can also explain these feelings by means of the effect that the sensation produces on our state of mind. What directly (through sense) urges me to leave my state(to go out of it) is disagreeable to me--it causes me pain: just as what drives me to maintain my state(to remain in it) is agreeable to me, I enjoy it. But we are led along irresistibly in the stream of time and in the change of sensations connected with it. Now even if leaving one point of time and entering another is one and the same act(of change), there is still a temporal sequence in our thought and in the consciousness of this change, in conformity with the relation of cause and effect. So, the question arises, whether it is the consciousness of leaving the present state, or the prospect of entering a future state, that awakens in us the sensations of enjoyment? In the first case the enjoyment 
is nothing else then the ending of a pain and something negative, in the second it would be presentiment of something agreeable, therefore an increase in the state of pleasure, consequently something positive. But we can already guess beforehand that only the first will happen: for time drags us from the present to the future(not the reverse) and the cause of our agreeable feeling can only be that we are first compelled to leave the present, without any certainty into which other state we will enter, knowing only that it is definitely another one. Enjoyment is the feeling of the promotion of life: pain is that of a hindrance of life. But(animal) life, as physicians also have already noted, is a continuous play of the antagonism of both. Therefore pain must always precede any enjoyment: pain is always first. For what else but a quick death from joy would follow from a continuous promotion of the vital force, which cannot be raised above a certain degree anyway? Also, no enjoyment can immediately follow another: rather, because one and another pain must appear. Small inhibition of the vital force with advancements in it constitute the state of health that we erroneously consider to be a continuously felt well-being..Pain is the incentive of activity and in this, above all, we feel our life, without pain lifelessness would set in." (A P.126)

This is a very concrete, descriptive account of the consciousness of pleasure and pain. Note the role of causation and the surprising claim that pain is the great initiator of activity. This corresponds with the Freudian claim that pain is the great educator of mankind as well as the Aristotelian claim that learning associated with pain (pity and fear) in works of art has a cathartic function, restoring the equilibrium of the appreciators of tragedy. The Aristotelian theory of change also suggests itself and there is no reason, in our view, why the above could not function as the energetics of our experience of change. If reality is a potential continuum for Aristotle, then experienced pleasure and pain are possible actualised points on any continuum of life. Paul Ricoeur, in his work "Freud and Philosophy: an essay in Interpretation" points out that Freud's theory is composed of an energetics of the psychical apparatus and a hermeneutics that follows from an interpretation of the symptoms of mentally ill patients. The energy regulation principle(ERP) and a network of concepts including "psychical apparatus", "cathexis", "anticathexis", "quantity", "excitation", "storing", "emptying" "homeostasis", and "tension" all testify to a materialistic substrate of mental functioning which Freud uses in certain kinds of explanation for certain kinds of phenomena. Freud refers to the ERP as the principle of constancy that he characterises in terms of the tendency of a system to maintain levels of energy as low as possible. The system, however, cannot eliminate all energy because the psychical apparatus: "must learn to tolerate a state of quantity sufficient to meet the demands of specific action."(Freud's unpublished Project P. 358) In the Project Freud refers to a particular system of neurones whose task it is to transform what he calls "Quantity (a seemingly un-measurable form of energy) into consciousness and its "qualities". In this "Project", we can also find an echo of Kant's account of the mechanics of the operation of pleasure and pain: 
"Since we have certain knowledge of a trend in psychical life towards avoiding unpleasure. In that case, unpleasure would coincide with a rise in the level of quantity" (Project P. 358)

What requires more elaboration in the above account is the role of the external world in relation to the demand for specific action: An external world which consciousness experiences qualitatively. In the process of avoidance of unpleasure, or, in other words, in this learning process, consciousness is the key factor. The ERP or constancy principle's function is to assist in testing reality for its qualities, and to inhibit certain primary psychical processes (such as hallucinatory wishing) from accessing the motor system. Energy is obviously "directed" in this process of inhibition with help from the ego. The suggestion from Freud here is that language plays the role of a secondary sensory source that expresses what Freud referred to as "thought-reality". We are here in the realm of what he called the operation of the "secondary process": the most secure form of thought process. This process is obviously closely linked to language or indications of speech. Freud claims interestingly, in this discussion that theoretical thought does not give rise to un-pleasure as is the case with the biological realities steered by the ERP and the pleasure-pain principle (when hallucination and perception are confused). The ERP and its relation to both primary and secondary processes have a key role in the formation of memory and its availability to consciousness in processes of reality testing and learning. High levels of anxiety (forms of unpleasure) will obviously prevent the formation of natural memories that emerge in reality testing and learning situations. High levels of anxiety appear to initiate secondary inhibitions that absorb some of the energy at the disposal of the ego and the "I think". In this context, we should recall that Freud in his first therapy attempts, thought it sufficient to revive the "traumatic memory" in a state of semi-consciousness (via hypnosis) in order for symptoms to disappear. This obviously was a necessary first stage in his cathartic process but it proved to be insufficient to integrate the anxiety-laden "image" into more abstract language governed thought processes where displeasure is neutralized. The use of hypnosis in this cathartic process was of course not helpful because it placed the subject in a superficial state of sleep where the language of the therapist was being used suggestively and the language of the subject was being used automatically. This method was obviously only partly effective and pushed Freud toward the development of techniques that demanded that the subject be fully conscious. The new techniques that were developed were: free association, recounting of dream memories, symptom interpretation, together with the transference relation to the therapist and they were all designed to embed old primary process images in secondary process "thought reality". Underlying the above practical innovations was obviously a theory of how the mechanism of pleasure and pain were operating in relation to the continuum of biological and thought processes. Energy regulation involving the transference and displacement of psychical energies were obviously 
important aspects of pleasure and pain regulation. Dreams, for example, may, if the theory is correct, be transformations of waking linguistic indications of thought into images that resemble hallucinations. Dream images also condense and displace representations and dream interpretation requires an understanding of the underlying mechanisms in the work of the dream. Freud treats dreams as symbols that require special interpretation. The path of this interpretation is laid down by the therapist who follows the dreamer's conscious free associations to each of the image-elements of the dream. Somatic excitations during sleep, residues of the day in the dream, and the wish to sleep also need to be considered in the dream interpretation process. It is, for example, the powerful biological energy-regulating wish to sleep that converts external stimuli into images and creates the effect of hallucination and de-realization of the body. This hylomorphic view of the mind results in the iceberg model of the mind where consciousness is the tip and the substance (the preconscious and the unconscious) resides beneath the surface of consciousness. The unconscious is clearly the most primitive aspect of the whole system but it is the reservoir of energy for the rest of the system, containing not just the death instinct of the melancholic but also the life instinct of the human race. Consciousness is in fact a vicissitude of these preconscious and unconscious aspects of our mind. In other words, the Freudian mental apparatus contains Aristotelian "forms". Hylomorphic theory permitted Aristotle to claim, for example, that "a dream is thinking that persists in the state of sleep". Freud would have agreed with this and this was the reason he concentrated much of his therapeutic efforts on the interpretation of the dream. He situated the biological wish to sleep and the residues of the day in the subconscious systems together with latent instinctive wishes that energised the dream formation. These latter were clearly situated in the unconscious system that for Freud operated on laws or principles, which were free of logic and time conditions. It is this unconscious element in the dream that gave the images contained therein their hallucinatory quality, their quality of being unreal. Here the psychical apparatus is operating on the substrate of the ERP but also seemingly in a different dimension. Memories, when reality-tested by motility with the assistance of language, become more real and find a natural home in the preconscious system where Freud also locates the meaning of words and all forms of knowledge. In Chapter 7 of his work "The Interpretation of Dreams," Freud provides a diagram of the psychical apparatus with memory close to the perceptual end of the apparatus and the preconscious system closer to the opposite motor end of the apparatus. Just behind the preconscious system, Freud places the unconscious system. The diagram seems incomplete. Where, for example, should one place the Kantian faculties of the understanding and reason? Since perception is the bearer of consciousness perhaps the Kantian faculties should be placed between perception and memory. Language also needs to be placed somewhere on the continuum of this apparatus. Since meanings of words are located in the preconscious system, perhaps language belongs within the preconscious system which 
we should recall is the faculty of thought-reality for Freud and also turns unpleasure or pain away from its activity. The key element of the above diagram of the psychic apparatus is clearly, for Freud's purposes, the unconscious system that contains the instincts and the life force needed for the actualising of the potential of humankind. One of the major tasks of the psychical apparatus as a whole is to develop a strong ego that is connected with what Freud regards as a task of "becoming conscious". Consciousness is, therefore a task for Freud. On an Aristotelian reading of Freud's life force, it appears to possess a telos, a potential that may never be realised. Paul Ricoeur claims that the instincts are "The Kantian transcendental X" of the Freudian system of thought. We referred earlier to the source, aims, and objects of instincts. The sources of instincts obviously fall in the domain of biology to investigate, and aims and objects appear to be the proper domain of investigation for Psychology (as conceived by Freud). From the point of view of Freudian energetics, Instincts are the source of the distribution of energy between the ego and its objects. They are also the reservoir of indestructible desires. If all this is in the name of transcendental psychology then we need to return to Kant to see exactly how the two accounts can complement each other. The closest Kant comes to this kind of psychology is in his remarks on mental illness and the mechanics of pleasure and pain but there are also some indications in book 3 of his Anthropology that might assist in this matter. In the section entitled "on the Faculty of Desire" Kant has the following to say:

"Desire (appetitio) isthe self-determination of subjects power through the representation
of something in the future as an effect of the representation. Habitual sensible desire is
called inclination. Desiring without exercising power to produce the object is wish. Wish
can be directed towards objects that the subject himself feels incapable of producing,
and then it is an empty(idle) wish. Inclination that can be conquered only with difficulty
or not at all by the subject's reason is passion. On the other hand, the feeling of pleasure
or displeasure in the subjects present state that does not let him rise to reflection(the
representation by means of reason as to whether he should give himself up to it or
refuse it) is affect. To be subject to affects or passions is probably always an illness of the
mind because both affect and passion shut out the sovereignty of reason. Both are also
equally vehement in degree, but as concerns their quality they are essentially different
from each other, with regard both to the method of prevention and to that of the cure
that the physician of souls would have to apply." (A P.149-150)

The above reference to a physician of the soul is suggestive of the possibility that in the society of Kant's time there were people prepared to fill such a role: the Enlightenment's forerunners to our modern-day psychoanalysts and psychologists. So even though Kant's classifications and descriptions take us no further into the Freudian depths of the mind, the above quote clearly takes us to the mouth of the Freudian cave, points to the darkness within, and invites the thinker inside in accordance with the suggestions of Plato's Republic where those of us enjoying the Platonic sun have an obligation to return to the depths of the cave and help the 
prisoners therein to their freedom. But what, then, is Transcendental Psychology? It clearly has Aristotelian, Kantian and Freudian elements. It is, as we have seen with Kant's account, a philosophical appeal to faculties and powers of the mind and related psychological processes. Answering this question, however, is fraught with difficulty because, many scientists and philosophers throughout the ages have been critical of transcendental and metaphysical theorising. The term "psychologism", for example, has been a common accusation by Philosophers of Kant's work: Less friendly terms have been used of Freud's work by scientists working in the positivistic tradition of investigation. Patricia Kitcher in her work "Kant's Transcendental Psychology" asks the question "What is Transcendental Psychology?" and in the process of defending Kant's work has the following to say:

"Powerful currents within and without Kant scholarship have combined to keep transcendental psychology out of the mainstream, beyond the pale of serious philosophical discussion." (P. 5).

One must agree with this judgment and perhaps add to this the fact of the reception that Freud's work received at the hands of both Science and Empirically oriented Analytical Philosophy. One of the criticisms of Kant that Kitcher refers to is the fallacy of attempting to found normative principles on factual premises:

"what might be called "strong" psychologism in logic: the attempt to establish the validity of logical principles by appeal to facts of human psychology" (P. 9).

There is, as she puts it no evidence of this problem in Kant but paradoxically accuses Kant of what she calls "weak psychologism" which she defines thus:

"The view that psychological facts may be important to philosophical normative claims, even though they cannot establish such claims." (P.9).

Given Kant's definition of reason in terms of the search for the totality of conditions of any state of affairs, it is difficult to appreciate the point Kitcher is making here. Kant in his logic operates with not just the principle of noncontradiction but also a principle of sufficient reason (which includes reference to necessary and sufficient conditions). In this sense, Kant's subjective deduction relating to faculties of the mind and their associated psychological processes may certainly be amongst the necessary conditions establishing, for example, the categories of the understanding that operate in accordance with both the principles of non-contradiction and sufficient reason. This is Kant's view of logic and it suffices to establish a relationship between psychological processes and logical claims. Kitcher goes on to claim, correctly, that twentieth-century psychology has been a force of opposition against transcendental psychology, but she does not attribute this to the philosophical movements of logical atomism and logical positivism that were flourishing at the time. Instead, she points out that: 
"Finally the ideology of twentieth-century psychology has had highly negative implications for the status of transcendental psychology. Assuming that introspection was the only way to study mental processes J. B. Watson and other behaviourists convinced their colleagues that they could write psychology and "never use the terms "consciousness", "mental state" "mind" "content" "imagery" and the like." (Kitcher P.10).

The roles of methodology and observation were discussed earlier in relation to the shift in the definition of psychology from the science of consciousness to the science of behaviour. The effect was to undermine the principled approach to Psychology that was begun by Aristotle and continued by Kant and Freud, an approach that did not, as was falsely claimed, rest on a mystical operation of introspection that "revealed" psychological phenomena. In the wake of this scientific movement everything apriorí (independent of experience) was regarded as actually innate rather than potentially actualisable(Aristotle) and the resultant concept of mind was described and explained in mechanical terms such as "systems", "modules", "processes" "input", "output" etc. Kitcher ends her account by claiming that psychologists have now realized that they cannot explain human behaviour without appealing to cognitive processes. She is, however, referring here to modern cognitive psychology (rather than that of Piaget's hylomorphically inspired psychology). Her view retains the right to regard the mind as a machine, a computer, thus undermining the fundamental feature of the Aristotelian, Kantian, and Freudian concept of mind as organic and alive. In a section entitled "Kant against Psychology" Kitcher points out that Kant criticises any appeal to empirical psychology in transcendental or metaphysical contexts. Her approach is a more subtle form of the criticism we find in Brett's History of Psychology, where it is claimed that Kant is to be held responsible for an empirical obsession with measurement in psychological experiments because, he claimed, that all serious science must have mathematics associated with its methodology. Brett has this to say:

"Kant's second contribution to the German tradition of psychology was his contention
that science is characterized by mathematical as well as an empirical description. His
celebrated fusion of the empirical standpoint of Hume with the rationalist standpoint
of Wolff involved the aphorism that an empirical inquiry is as scientific as it contains
mathematics. This was an extrapolation of Newtonian practice and as a methodological
prescription, it had a profound effect on successive psychologists. It introduced the craze
for measurement in psychology and reinforced the yearning for scientific respectability
amongst psychologists which had started with Hume's treatise." (Peters P. 533).

Brett also fails to appreciate the complete account of Kantian science which would refer to an empirical level of measurement that is connected to transcendental and metaphysical principles and laws: an account that acknowledges the role of observation and measurement in investigations into what he termed the phenomenal self that can be postulated as a substance and observed in a causal framework. This account, however, does not suffice in Kant's view to bring us into contact with 
the transcendental noumenal self that thinks. Brett believes this approach to be contradictory because he believes two selves are being evoked, and one of these selves (the noumenal metaphysical self) is not a possible object of study. Kant would also deny that the noumenal self is a possible object of study, on the grounds that the "I think" is the ground of the possibility of studying objects using understanding and reason and cannot, therefore, study itself as an object. For Kant, the phenomenal self and the noumenal self are two different ways of characterising the self, and even if mathematics might be used in observations of the self, it could not study thought because thought was not accessible empirically. Brett refers to Kant's remarks on the relation of science and mathematics as a prejudice:

"The combination of observationalism with the Kantian prejudice about mathematics encouraged the view that science progresses by the accumulation of measurements, the noticing of laws or correlations between the sets of measurements, and the final relating of laws under theories. Psychologists, increasingly self-conscious about the status of their studies thought that respectable scientific theories would emerge only if enough mathematics was used in making the initial observations." (P. 534)

It is difficult to fathom exactly what Brett meant by the Kantian prejudice in favour of mathematics. Mathematics measures substances in space (geometry) and in time (number). Kant clearly says that neither the self nor the soul is substance, echoing the Aristotelian claim that they are "forms" or "principles". One cannot measure principles but a principle may well help to determine the consciousness that contains "qualities" of reality that may then be quantified and turned into measurements (red is ca. 690-angstrom units). If the "I think" entails that I must be thinking something about something on the condition that I am thinking conceptually, then concepts must express the qualities of the something that we find in the subject position of the thought or judgment. There is no substance here to be measured, and Kant criticised rationalist psychology for using this assumption. Brett after the above criticism, surprisingly confirms the Kantian objection to substance in the following quote:

"Kant saw that it was not possible to speak of a soul which entered into a relationship
with a system of pre-existing things. That consciousness which Descartes put in the
forefront of his speculations is not for Kant a function of the soul: on the contrary, the
new attitude is clearly defined by the assertion that the soul, in this sense, is in the
consciousness, it is an idea. Hume had perhaps taught Kant that reflection never is
withdrawing of the soul into itself, nor is it a power by which the soul observes itself."
(P.537-8)

This acknowledgment does not, however, quite fit with the criticism above. It has to be said that if the characterisation of Kant's position by Brett is correct, then it almost looks as if Kant shares the Freudian view that the task of a person is to "become conscious", to 
actualise the potential within, to use Aristotelian language. Brett continues his theme of a "psychology without a soul" in the following interesting quote:

"Here, then, is the real beginning of "psychology without a soul". In distinction from many who have used that phrase, Kant did not propose to deny the reality of the soul in the same way in which it had been asserted: his treatment of Rational Psychology is not dogmatic but critical. The first result was a clear conception of the limits of psychology: in place of the previous inaccurate use of terms we are given clear distinctions. The science of the soul is called Pneumatology: the study of man as part of nature is called Anthropology: under Anthropology in general comes the specific department called Psychology." (P.538)

This is not the clearest characterisation of Kant's Anthropology and Brett's reference to "we are given clear distinctions", whilst correct, is inadequately so, because we are only given clear distinctions in virtue of their relation to clear principles. It is, in particular, not clear from the above that the Anthropology (from a pragmatic point of view) is not a theoretical empirical inquiry. What is clear is that Psychology is best conceived as a practical inquiry presupposing a priori principles. In becoming conscious (Freud) or becoming rational (Aristotle) man uses his freedom to make something of himself. Brett does not acknowledge this aspect of Kant's argument. He continues to believe falsely that the Anthropology is primarily epistemological rather than ethical and therefore claims that everything appears to be "inner". Principles are neither inner nor outer, and Kant's Anthropology is a search for the principles of transcendental psychology in the spirit of transcendental philosophy. Recall again Kant's definition of Anthropology, "what man makes of himself". The reference to the ethical law of freedom is unmistakable and freedom is as manifest in outer behaviour as it is in the inner mental activity of choosing to act in one way rather than another. Brett notes the presence of the will in the third book of the Anthropology and remarks on how the feeling of pleasure and pain are sublimated by the ideas of good and evil that he claims come from the understanding and reason. All the above misconceptions then lead Brett to claim:

"Kant takes psychology to be of little value, it is for him wholly empirical and consists of an elementary doctrine of faculties amplified by the inclusion of such descriptive matter as might have been culled from novels or improving stories" (P. 541).

The only comment one can make about such a gross misreading is to perhaps point out that fictional works acknowledge the presence of the moral life and its relevance to Psychology to a much greater extent than anything Brett has to say on this topic. Brett then equally paradoxically claims that Kant's ideas herald the science of behaviour. The grounds are not entirely clear but have something to do with the role of sensation in Kant's theories. Brett claims that sensationalism is correct provided that it is critical (whatever that means) and claims that it is difficult to fathom what Kant means with 
his idea of sensation. It is, however, no more difficult to fathom what Kant meant than it is to understand Aristotle's view. All that is needed is an understanding of the hylomorphic theory where form once actualised can become matter for the next stage of the actualisation process of a life form. Sensation is one form taken by consciousness when the nervous system of a life form is activated and it can take a simple form without any attachment to an object, when, for example, I am feeling cold (I am not feeling cold at anything). Sensation can also take a more complex form if we are talking about the feeling of anger when, as Aristotle points out, it takes as its object some insult. It can take yet another even more complex form when it is the feeling caused by an object of free beauty when the faculties of the understanding and the imagination are "felt" in their free play. Brett surprisingly acknowledges this Aristotelian influence on Kant in the following remark: "Kant rightly declared that the mind must be regarded as a structure regulated by principles which are ultimately its own activities."(P.544). The reference to principles is certainly both Kantian and Aristotelian but the implication that principles and activities are somehow identical is to say the very least paradoxical. The principles are of course principles in transcendental logic, and denote not activities themselves, but the conditions of activities. Brett does not believe in the categories of understanding, meaning that he does not believe they can be established either logically or psychologically. Kant's work on the categories, as we know relates to the different logical forms of judgment that are used to generate true statements. We also know this was the part of the First critique that he spent most of his time on. Brett follows up with the criticism that Kant is confusing psychology with logic: a position that Kitcher in her work, dismissed. In 1921 it might have seemed like "good news" that science was not going to bear the burden that philosophy bore earlier and Psychology at that point in time was barely 50 years old. Nothing much has happened in the name of scientific psychology almost one hundred years later. Brett was one of the bearers of the good news but is now one of the targets of those philosophers who have been influenced by the work of Aristotle, Kant and Freud. We can even, somewhat paradoxically, add another philosopher to that list, namely, Wittgenstein. Wittgenstein's earlier work was in logical atomism and he also flirted for a short period with logical positivism. In his more mature position, Wittgenstein, claimed that Psychology as a discipline was rife with conceptual confusion. It is interesting to note in this context the respective dates of publication of Wittgenstein's earlier work ("Tractatus LogicoPhilosophicus") and Brett's History of Psychology were 1922 and 1921 respectively. By 1950 Wittgenstein had reversed his position and both Logical atomism and Logical positivism as movements had been overshadowed. Wittgenstein's "Tractatus" used the key terms "object "and picture": terms favoured by the empirical psychology of the time. At the end of this work, Wittgenstein was forced to admit, after defining the world as the totality of facts, that the sense of the world mysteriously lay outside the world, and also that all forms of value lie outside the world. Ethics, aesthetics, and religion found themselves in the realm of what cannot meaningfully be said because 
the only meaningful propositions were those of natural science. Kant would, of course, have substantially criticised the picture theory of meaning contained in the Tractatus, which built upon the "fact" that we form pictures to ourselves of those facts. These pictures were a work of construction by an imagination faculty not connected to an active will that seeks to understand and reason about its representations (a will that also, according to the Tractatus lies outside the world). So, even in his early work, we see in Wittgenstein a forced acknowledgment of transcendence, but we also find very little transcendental psychology except perhaps in his claim that the world of a happy man is a different world to that of the unhappy man. Wittgenstein retreated in his later work from Science and his mystical form of transcendence, and moved toward a position that favoured a position that regarded forms of life(Aristotle) and languagegames as primary concepts. Yet, even after eschewing science he was still in search of a "method" in Philosophy and claimed that one had been found in his grammatical investigations. These investigations offered us a kind of transcendence in that they provided us with the essences of things in some a priori fashion. This is not exactly the transcendental method of Kant where it is claimed that transcendental knowledge is not concerned so much with objects of experience as with the manner of knowing these objects, (a manner that requires the acknowledgment of representations that have an a priori character.) So while Wittgenstein seeks the a priori principle and origins of our judgments and activities in language and forms of life, Kant continues to place his faith and hope in reason and uses legal deductions that prove the right to use concepts involved in different kinds of knowledge claims. A priori concepts, it is true, do not derive from sensations and Kant specifically implies this. But nevertheless, the psychological and scientific response to Kant's claims in this area is to project upon him a position that he does not adopt, namely that a priori concepts are "innate", in spite of the extensive written evidence to the contrary, especially that contained in the socalled Eberhard controversy:

"The Critique admits absolutely no divinely implanted or "innate" representations... there must, however, be a ground in the subject which makes it possible for these representations to originate in this and no other manner...This ground is at least innate." It is, in other words, the power that has the potential to be exercised or used which is part of the "form" of the organism, part of its life form. This form, then, includes the potentiality for cognitive tasks of consciousness that involve the use of the categories of judgments/understanding and the ideas of reason. We are here in the realm of what Kant called synthetic a priori propositions that cannot be proved by formal logic. The predicate concept is clearly not contained in the subject concept in these judgments. The proof required for synthetic a priori propositions, is a transcendental proof: the proof proves that the negation of a synthetic a priori proposition is a kind of contradiction thus proving the universality and necessity of the proposition. Kitcher summarizes this well by saying: "transcendental investigations of the sources of knowledge--transcendental psychology-- disclose universal and necessary features of human cognition." (P.19). 
She continues, however, by pointing out that Kant had no understanding of the twentieth-century discipline of computer science suggesting that his philosophy somehow supports such a discipline. A computer is not a life form, it merely imitates life forms in a manner that is neither transcendental nor ethical in that it possesses no freedom to choose to attend to this rather than that. For Kant, the matter constituting something of substance is very relevant to its function, especially if this something is a life form. A computer for Kant may be able to imitate conscious function but is not conscious in the way we are. Our organs, for example, are in possession of the kind of chemistry, biology, and physiology that a computer does not possess. It is the system of our organs (including a brain), on the hylomorphic view, that constitutes our human form of consciousness. For Wittgenstein too, (for whom the concept of the form of life was important), we would be witnessing a conceptual confusion if one believed that Kant's philosophy could not explain or justify the cognitive tasking of a computer. Kant would certainly agree, if provided with knowledge of computers, as would many philosophers, that artificial intelligence does not resemble real human intelligence in any significant respect. The computer may be able, in accordance with the Turing test, produce the same results as a human Chinese translator but it remains an incontestable fact that the computer does not understand Chinese, and the reason for this state of affairs lies in the different material embodiment of the cognitive function we are witnessing.

\section{Bibliography}

1. Kant, I., Anthropology from a pragmatic point of view, Translated by Louden, B., R., (New York, Cambridge University Press, 2006)

2. Kant, I., Critique of Pure Reason, Translated by Kemp Smith, N., (London, Macmillan Press, 1929)

3. Kitcher, P., Kant's Transcendental Psychology (Oxford OUP, 1990)

4. Peters, R., S., Brett's History of Psychology, Edited and abridged by R S Peters, (Massachusetts Institute of Technology, 1953)

5. Peters, R., S., Psychology and Ethical Development, (London, Allen and Unwin, 1974)

6. Ricouer, P., Freud and Philosophy: an essay in interpretation(, Translated by Savage, D., (New Haven, Yale University Press) 